\title{
HERMENÊUTICA FILOSÓFICA E PROCESSO: UMA REFLEX̃̃o CRÍTICA ACERCA DAS REFORMAS DO CÓDIGO DE PROCESSO CIVIL BRASILEIRO
}

\author{
PHILOSOPHICAL HERMENEUTICS AND PROCEDURE LAW: \\ A CRITICAL REFLECTION ABOUT THE BRAZILIAN CODE OF CIVIL \\ PROCEDURE'S REFORMS
}

\author{
Julia Lafayette Pereira* \\ Jânia Maria Lopes Saldanha**
}

\begin{abstract}
RESUMO: O presente trabalho tem como escopo analisar o paradoxo entre os valores eficiência e efetividade presentes no cenário das reformas do Código de Processo Civil brasileiro. O Direito, e mais especificamente o modelo processual de herança romano-canônica, mergulhado no paradigma Racionalista, propicia um terreno fértil para que se cultivem mitos que, ainda que aparentem o compromisso de tornar o Judiciário mais rápido e eficiente, encobrem - sob uma aparente neutralidade - a ideologia a qual prestam serviço: o neoliberalismo. Por isso, essencial é a superação do paradigma cientificista e matemático pela hermenêutica filosófica, com o intuito de se alcançar uma reflexão do Direito, bem como do sistema processual como um todo, não distante e não dissociado do mundo vivido ou da realidade concreta. Ademais, necessário é também, pensar-se o Direito não apenas vinculado à ideia de Poder, mas também à de Justiça, pois a Carta Constitucional de 1988, a qual o Direito Processual está sujeito, assume um forte compromisso moral de transformação social da realidade brasileira aspirando a uma sociedade mais democrática.
\end{abstract}

PALAVRAS-CHAVE: Racionalismo. Processo Civil. Neoliberalismo. Hermenêutica filosófica.

\begin{abstract}
The present study has as scope to analyze the paradox between the efficiency and effectiveness values present in the scenery of reforms of the Brazilian Code of Civil Procedure. The law, and more specifically the procedural model of Roman-canonical heritage, steeped in the rationalist paradigm, provides a fertile ground for myths to grow, albeit apparently committed to making the judiciary more quickly and efficiently, dissimulating - an apparent neutrality - the ideology which they serve: neoliberalism. So it is essential to overcome the scientific and mathematical paradigm to a philosophical hermeneutics in order to achieve a reflection about the law as well the system as a whole, not distant from the lived world. Moreover, it is also necessary to think the law not only linked to the idea of power, but also to justice. The Constitutional Chart of 1988, to which the procedural code is subjected, expresses a strong moral commitment to social transformation of the Brazilian reality, toward to a more democratic society.
\end{abstract}

KEYWORDS: Rationalism. Code of Civil Procedure. Neoliberalism. Philosophical hermeneutics.

* Mestranda em Direito Público do Programa de Pós-Graduação em Direito da Universidade do Vale do Rio dos Sinos - UNISINOS. Bolsista Capes/CNJ Acadêmico. E-mail: julialafayette@hotmail.com

** Pós-Doutoranda em Internacionalização do Direito no Collège de France. Doutora em Direito da Universidade do Vale do Rio dos Sinos (UNISINOS). Professora do Programa de Pós-Graduação em Direito da UNISINOS e Professora do Curso de Direito da UNISINOS e da Universidade Federal de Santa Maria (UFSM). E-mail: janiasaldanha@gmail.com 


\section{INTRODUÇÃ̃O}

São recorrentes as críticas feitas ao atual Código de Processo Civil brasileiro, bem como as exigências, por parte dos juristas, de que o sistema processual seja reformado. Ambas considerações são fortemente alimentadas pelo inconformismo com um sistema processual extremamente moroso, incapaz de acompanhar uma sociedade premida pela pressa.

À luz de uma compreensão hermenêutica das reformas que ora vem ocorrendo no Código de Processo Civil brasileiro, o presente artigo objetiva fazer uma análise que excede a mera discussão centrada nas questões de fluxo do Judiciário, que o diagnostica como ineficiente. Pautando-se pelo paradoxo entre eficiência e efetividade, o artigo também objetiva questionar o papel exercido pelas agências transnacionais de fomento a países periféricos em tais reformas, mais especificamente, aquele desempenhado pelo Banco Mundial.

Para tanto, no primeiro capítulo, o artigo lança-se a uma discussão acerca do Paradigma Racionalista, cujo sistema processual civil está imerso, retratando-se as estruturas sobre as quais ele se mantém - fortemente compromissadas com os valores iluministas de segurança e certeza.

No segundo capítulo, discute-se as consequências de tal paradigma no senso comum teórico dos juristas - porque estes (os juristas), nele mergulhados, são incapazes de compreender que o descompasso entre ciência processual e sociedade hoje vivenciado vai além de problemas pontuais, pois trata-se de uma crise paradigmática.

Com isso, busca-se demonstrar porque o pensamento jurídico guiado pela lógica das ciências exatas e distanciado da realidade é terreno fértil para o desenvolvimento de reformas processuais umbilicalmente ligadas ao neoliberalismo, o que reduz o Judiciário a uma função de outros interesses - econômicos - e distancia-o daquilo que lhe é tarefa mais valiosa à luz da Constituição de 1988: contribuir para a concretização dos direitos dos cidadãos assegurados na Carta e colaborar para a construção de um cenário mais democrático.

Dessa forma, utilizando-se como autores-chave Ovídio A. Baptista da Silva, HansGeorg Gadamer, Luiz Alberto Warat e Antoine Garapon para se refletir o sistema processual, tem-se como intuito, ainda, demonstrar como estes autores estão compromissados com um mesmo modo de se pensar o Direito.

\section{RENASCIMENTO, REFORMA RELIGIOSA E NOMINALISMO: O PENSAMENTO BINÁRIO RACIONALISTA}

Conforme Ovídio A. Baptista da Silva (2006, p. 57), o Direito Processual Civil brasileiro está fortemente estruturado à luz do paradigma Racionalista, cujo complexo 
fenômeno cultural foi gradativamente se consolidando no decorrer do final da Idade Média e surgimento da Idade Moderna. Para uma adequada compreensão do Racionalismo, é indispensável considerar os dois movimentos culturais de maior expressão ocorridos neste período: o Renascimento, e o importante produto cultural originado dele o humanismo, bem como a Reforma Religiosa (BAPTISTA DA SILVA, 2006, p. 58).

A delimitação temporal compreendida como Idade Média, segundo adverte Ovídio Baptista, compreende um intervalo de dez séculos ocorridos na história européia, que abrange desde o fim do Império Romano até o surgimento da Idade Moderna. Reconhece-se este período como Idade Média com mero intuito de propiciar uma melhor compreensão de pessoas situadas significativamente distantes desta época (BAPTISTA DA SILVA, 2006, p. 58).

Assim como não havia no homem medieval a noção temporal do período Idade Média, da mesma forma, o homem renascentista não era consciente de que o espírito de sua época estava a "desencadear as potências espirituais que provocariam a chamada Idade Moderna" (BAPTISTA DA SILVA, 2006, p. 59). É sob influência desta observação que se torna possível perceber a profunda ligação do homem moderno com o homem do medievo, assim como do Renascimento com a cultura clássica greco-romana.

Nesse contexto, Ovídio Baptista (2006, p. 59) sabiamente elucida que - muito embora um período histórico se distinga de outro em virtude de circunstâncias desconhecidas e inovações tecnológicas, como a descoberta de novos materiais, por exemplo - para tal distinção, mais relevante é o modo como o homem passa a compreender o acervo cultural herdado de seus antecessores, mediante um processo lento e quase imperceptível, porque gradual.

É por isso que, o processualista gaúcho afirma que um mesmo objeto histórico pode ser compreendido e interpretado de diversos modos, a depender do contexto histórico e espiritual a que está inserido o observador. Daí o paradoxo de que também o passado é plástico para a história, em oposição à ideia de um passado submetido a uma rigidez petrificada, entendimento próprio das ciências naturais (BAPTISTA DA SILVA, 2006, p. 59).

Bem se ilustra esta passagem, quando, invocando Agnes Heller, Ovídio (2006, p. 59-60) versa que Sócrates e Jesus são dois personagens formadores do paradigma moral Renascentista e afirma que as especificidades do período renascentista "tiveram origem basicamente em uma nova leitura das mensagens deixadas por ambos, mais do que em virtude de novas circunstâncias ou episódios culturais antes inexistentes". Assim, a aproximação entre tais personagens - Sócrates e Jesus - foi realizada porque ambos, como homens, sofreram sofrimentos análogos, bem como também eram padrões de conduta moral a serem seguidos. Neste período, antes de haver a santificação de Sócrates, o que verdadeiramente houve foi a humanização de Jesus. 
Tais considerações são de expressiva relevância porque o individualismo, próprio da ideologia moderna, é herdeiro do principal substrato espiritual do Renascimento - o Humanismo. Para Ovídio (2006, p. 60),

o Humanismo é a principal mensagem transmitida pela moral cristã, reorientada, porém, na doutrina medieval, especialmente a partir de Guilherme de Ockham, no sentido de um nominalismo absoluto como mostra o próprio Dumont, ao lembrar que o "arauto do estado de espírito moderno", em sua luta contra o Papa, foi ao ponto de negar que existisse algo como 'uma ordem franciscana'. Para ele, existiram apenas os 'monges franciscanos', dispersos pela Europa, não um universal, como uma "ordem franciscana". Do nominalismo dos monges franciscanos, para o individualismo moderno, a distância era insignificante.

Ovídio Baptista (2006, p. 61) afirma que foi no período renascentista que o homem se tornou um indivíduo espiritual, "pensando-se como uma entidade abstrata e universal", diferentemente do que ora vigorava: compreensão do homem enquanto raça, comunidade, corporação, família. Nesse sentido, a noção do homem como ser autônomo, individual é própria da modernidade, e fortemente influenciada pelo cristianismo, mais precisamente pelo processo da Reforma Religiosa.

Diferentemente da ciência aristotélica, que estava integrada na filosofia ${ }^{1}$, a ciência moderna pretendeu se construir independentemente da filosofia. Só que, devido à necessidade de uma unidade no pensamento humano, tal afastamento foi apenas aparente, e logo se construiu uma nova filosofia, porém estruturada em pressupostos completamente distintos dos clássicos.

Embora muitos digam que a grande novidade dos cientistas modernos fosse o fato de terem rejeitado a autoridade ${ }^{2}$, ou a experiência, Villey vê com reservas tais compreensões. No que concerne à experiência, essencialmente, o autor argumenta que ela também esteve presente na ciência moderna, e afirma que todos dela fazem uso, pelo menos a título de observação.

Nesse sentido, a experiência, em Aristóteles, consistia em uma observação do conjunto, do integral, "próxima da experiência vulgar, e que lhe permitia perceber no real qualidades (o quente; o frio; o pesado; o leve) e valores (como a harmonia dos conjuntos)" (VILLEY, 2005, p. 588). Por outro lado, nos modernos, a experiência é artificial e faz uso de instrumentos como luneta (Galileu), barômetro (Torricelli), microscópio, balança, entre outros. Mediante o uso de tais instrumentos, estas eruditas

1 Esta característica ainda permaneceu durante a escolástica, de acordo com Villey.(2005, p. 587).

2 Para Villey, "não é que os modernos tenham rejeitado a autoridade: também são Tomás considerava, em se tratando de ciência, a autoridade como o último dos argumentos, e não poderia ser diferente em qualquer pesquisa autêntica. Ater-se ao uso excessivo do argumento de autoridade era, da parte de Galileu ou de Gassendi, assim como de Bacon ou de Descartes, apenas um procedimento retórico para abalar o império de Aristóteles". (VILLEY, 2005, p. 587-588). 
observações só permitem perceber o que é mensurável na natureza, em outras palavras, o que é possível de se enquadrar em fórmulas matemáticas.

Pelo fato dos cientistas modernos só consideram o quantificável, a ciência se torna "pobre, fria e puramente objetiva" e, consequentemente, os valores desaparecem. Herdeira da teoria nominalista de Guilherme de Ockham, ela só observa o que é singular (ou fatos singulares), ignorando a harmonia dos conjuntos, própria à filosofia aristotélica. Nas palavras de Villey, "ela faz uso de uma lógica nova, de uma linguagem matemática, serve-se de indução e de dedução, mas não mais da antiga dialética apta a raciocinar sobre os valores e sobre qualidades tais como a qualidade do justo ${ }^{3}$ " (VILLEY, 2005, p. 588).

Contudo, cabe fazer uma ressalva: não se está aqui a repudiar os progressos técnicos propiciados pelas ciências modernas. Seu sucesso na astronomia, física, química ou medicina são incontestáveis. $O$ que se critica, precisamente, é o fato de ela haver se propagado por todos os outros setores do conhecimento que não os circunscritos pela Física. A adequabilidade dos seus métodos, quando aplicados ao Direito, é que são questionáveis. Bem se ilustra este ponto de vista quando se recorda a famosa frase do médico cirurgião que "declarava nunca ter encontrado a alma fazendo uso de seu escapelo" (VILLEY, 2005, p. 588-589).

Na obra Jurisdição e Execução na Tradição Romano-Canônica, Ovídio Baptista (2007, p. 118) bem destaca que o Direito, originalmente, não se confundia com a lei, nem, muito menos, com a ideia de poder, pois tal compreensão é produto da modernidade. Dessa forma, o conceito de "díké" que os filósofos gregos identificavam como Justiça, torna-se, cada vez mais, intraduzível em decorrência do sentido que modernamente se atribui à Justiça, consistente em uma obediência procedimental e formal daquilo que é prescrito e previamente ordenado, tal qual ocorre com os procedimentos científicos das ciências naturais (BAPTISTA DA SILVA, 2007, p. 119).

Ovídio Baptista assevera que os elementos da filosofia jurídica greco-romana foram conservados pelo jusracionalismo moderno na medida em que seus princípios

3 Franklin L. Baumer conta que "obviamente, cientistas e poetas expandiam-se juntos nesta nova natureza (das descobertas científicas). No entanto, entre cientistas e filósofos naturais, a ênfase incidia mais sobre o poder - o sentido do poder que os seus novos conceitos e métodos lhes davam. Assim, ao mesmo tempo que expressavam reverência pela natureza, como trabalho feito por Deus, falavam também do 'Reino do Homem', do ‘domínio' do Homem sobre a natureza. Não viam nisto uma contradição. Não criara Deus o homem à sua imagem, e a natureza para uso do homem? Todavia, a ideia do 'domínio' transmitia uma mensagem mais forte. Arrojada e agressiva, baseava-se na nova doutrina do Renascimento sobre a criatividade do homem e na confiança gerada pelas descobertas tecnológicas recentes, isto é, pela navegação, pela exploração e pelas invenções. Embora chamasse a atenção para a cobiça do poder, que causara a queda dos anjos, Bacon, no entanto, incitava à reafirmação do 'direito do homem sobre a natureza' e à extensão 'do poder e domínio da raça humana sobre o universo'. 'O fim de nossa fundação', diz o director da 'Casa Salomão', a Academia Científica da Nova Atlântida, a utopia de Bacon, 'é o conhecimento das causas e dos movimentos secretos das coisas, e a expansão dos limites do domínio humano, para a realização de todas as coisas possíveis"” (BAUMER, p. 77). 
puderam ser condicionados por esta nova ordem filosófica. Nesse sentido, o autor elucida que "o direito racional moderno, por exemplo, privilegiou apenas uma das formas de justiça preconizada por Aristóteles", privilegiando apenas a justiça comutativa aristotélica, e precariamente associando-a a justiça distributiva. Isto em razão da justiça distributiva exercer um papel essencialmente transformador, o que destoa dos valores consolidados no novo ordenamento jurídico concebido, que prioriza - sobretudo - a segurança jurídica, e - por consequência - a perpetuação do status quo (BAPTISTA DA SILVA, 2006, p.68).

O significado atribuído à palavra "diké" por Homero e pelos filósofos contemporâneos a ele, "pressupunha que o universo tivesse uma única ordem fundamental, uma ordem que estruturava a natureza e a sociedade, de modo que a distinção que nós fazemos ao contrastar o natural ao social não podia ainda ser expressa" (BAPTISTA DA SILVA, 2007, p. 118). Nesse contexto, a utilização de "diké" pelos filósofos da Antiguidade, direcionava-se a um universo sujeito a uma única ordem fundamental, que estruturava tanto a natureza como a sociedade. Destarte, a cisão entre natural e social modernamente presente, era inconcebível àquela época.

O termo "Díkaios", ou seja, o que se pressupunha como homem justo, significava orientar-se de acordo com a ordem natural do universo, diferentemente da ideia moderna de homem justo como aquele que age de acordo com a lei - compreendida esta como o "mandamento arbitrário criado pela vontade do soberano" (BAPTISTA DA SILVA, 2007, p. 118).

Assim sendo, um estudo sério do Direito Processual brasileiro, que se dirija a uma análise crítica das suas estruturas, não pode ser realizado sem que se considere a ideologia da modernidade, que ao colocar o indivíduo como centro de tudo, denota a influência medieval, que originou a própria noção de direito subjetivo. Nesse contexto,

é importante considerar que, em nossas atuais circunstâncias, não são mais - ou talvez nunca tenham sido - os indivíduos, considerados em si mesmos, os sujeitos da História. As verdadeiras forças sociais estão representadas pelos grupos. Todavia - isto é o que nos importa - as instituições processuais, tais como foram concebidas, permanecem tendo o indivíduo como seu protagonista (BAPTISTA DA SILVA, 2006, p. 61).

Não se pode também olvidar a influência do modelo capitalista no nosso modelo de Processo Civil. Consoante com o pensamento de Max Weber, Ovídio Baptista evidencia que, embora o desenvolvimento de cunho racional da filosofia seja anterior ao modelo capitalista, este se apropriou desta filosofia cientificizante e a lançou nas estruturas do seu modelo econômico.

No entanto, Ovídio Baptista faz uma importante ressalva: não foram os países que alcançaram o maior nível de racionalização econômica que, proporcionalmente, alcançaram uma expressiva racionalização do Direito, como Inglaterra e demais países do norte da Europa. A racionalização do Direito está fortemente presente nos países da 
Europa meridional, mais precisamente nos países católicos, "herdeiros da tradição formada pelo Direito Romano tardio" - ainda que não tenham acompanhado o progresso material dos países nórdicos (BAPTISTA DA SILVA, 2006, p. 62).

Atribui-se a existência de tal diferença devido ao fato de que, nos países do norte da Europa, principalmente na Inglaterra, o poder das grandes corporações superou o Renascimento do Direito Romano tardio, em oposição aos países meridionais, em que ele se desenvolveu e exerceu forte influência. Do mesmo modo, Ovídio ressalta que os pressupostos políticos da monarquia absolutista e a consequente reação liberal que ensejou a Revolução Francesa condicionaram o Direito dos países continentais, pois influenciados pelos ideais revolucionários - construíram um modelo processual de cunho científico, do qual somos herdeiros. Esta é uma circunstância que distancia o direito continental do common law.

Angela Araujo da Silveira Espindola (2008, p. 56) afirma que as ciências humanas se apropriaram dos métodos científicos desenvolvidos nas ciências naturais-exatasmatemáticas (Galileu, Descartes, Newton), com o intuito de servir aos valores modernos: segurança e certeza. Desse modo, a autora elucida que

o estatuto epistemológico e metodológico das ciências naturais era (e continua sendo) aplicado indistintamente às ciências sociais e humanas. Estudam-se os fenômenos sociais como se fossem fenômenos naturais, trata-se o direito como se fosse algo previamente dado ao homem, restandolhe indicá-lo (o direito) e aplicá-lo. Os fatos sociais reduzem-se às dimensões externas, observáveis e mensuráveis. $\mathrm{O}$ direito é examinado com luneta ou colocado em tubos de ensaio. A ciência moderna determinou o modo de ser e o agir do ser humano contemporâneo, pregou o desenvolvimento moral e material do homem pelo conhecimento (ESPINDOLA, 2008, p. 59).

Em consonância com José Reinaldo de Lima Lopes, Angela Espindola (2008, p. 59) afirma que o processo cientificizante do Direito culmina com uma "falácia da naturalização" e uma "falácia da evolução", pois se acredita que a razão moderna, científica e racional, seja a única capaz de resolver as insuficiências do Direito. Assim, acredita-se ter sido alcançado o melhor modelo de sistema jurídico - perfeito e acabado considerando, inclusive, os modelos antecedentes como meras experiências históricas preparatórias. Desconsidera-se, até mesmo, a possibilidade de alternativas melhores a este modelo.

Com base nisso, Angela Espindola (2008, p. 59) questiona se o modelo pensado para os desejos da humanidade presentes no século XVI, atingiu o seu ápice na modernidade. Bem como, pergunta-se se chegamos a Ilha da Utopia, pensada por Thomas More, em que existe um "sistema social, legal e político perfeito, guiado pela razão", de forma que tenhamos transportado o paraíso para o mundo real. Argumenta parecer que não.

O raciocínio universalizante, próprio do século XVIII, e a matematização das ciências sociais propiciam o esvaziamento de sentido e o empobrecimento do significado, 
enobrecendo-se o método. Guiado por este modelo, o Direito é apenas fato, e não há apreciação axiológica do seu conteúdo, o que inviabiliza a compreensão hermenêutica (ESPINDOLA, 2008, p. 59). No entanto, tendo-se em consideração a dimensão problemática do Direito, torna-se insustentável estudar o Direito com base no que Angela Espíndola denomina como padrões epistemológicos próprios das ciências naturais.

Por isso, tem razão Hans-Georg Gadamer (2003, p. 20) quando, reivindicando a necessidade de uma teoria autônoma para as ciências humanas, afirma que a teoria das ciências humanas não pode se reduzir à simples metodologia de um determinado grupo de ciências, pois ela deve ser eminentemente filosófica "e num sentido bem mais radical do que, por exemplo, a metodologia das ciências da natureza". Nesse contexto, Gadamer argumenta que as ciências humanas não devem se limitar a pôr um problema para a filosofia, mas, na verdade, a pôr um problema de filosofia.

Com isso, para Gadamer, o papel filosófico a ser desempenhado pelas ciências humanas segue a lei do tudo ou nada. Melhor explicando: de nada adiantariam se fosse dito que elas são apenas realizações imperfeitas diante de uma "ciência rigorosa", pois desta compreensão seguiria a ideia de que também a filosofia dita científica se pautaria pelos critérios das ciências matematizadas da natureza, reconhecendo-as, inclusive, como norma científica. Por outro lado, se as ciências humanas forem reconhecidas como um modo autônomo de saber, e se for reconhecida a impossibilidade de serem submetidas ao

ideal de conhecimento próprio às ciências da natureza (o que implica considerar absurdo tratá-las segundo o ideal de semelhança mais perfeita possível com os métodos e graus de certeza das ciências da natureza), então é a própria filosofia que está em questão, na totalidade de suas pretensões (GADAMER, 2003, p. 20).

\section{A INFLUÊnCiA do RACIONALISMO SOBRE O PROCESSO DE PERFIL NEOLIBERAL: EM BUSCA DE UMA COMPREENSÃO HERMENÊUTICA PARA O DIREITO PROCESSUAL}

Luiz Alberto Warat (1994, p. 104) muito bem retrata o estado da arte exposto no primeiro capítulo quando relata "que o mito em sua significação mais arcaica, pode ser visto como um processo de compreensão do mundo", compreendendo-se por mito a razão científica moderna na qual estamos mergulhados. Nesse sentido, segundo Warat, substitui-se o tempo histórico por fábulas cujo papel visa demonstrar ações e acontecimentos como protótipos eternos "ritualmente" já alcançados. Faz-se uma análise fatalista da História, de modo análogo à manifestação fatal da natureza, compreendendo-se a História como um resultado previsível, pois condicionado pela razão universal. Dessa forma, explica $\mathrm{W}$ arat que o mito se apresenta como fora e acima 
do seu tempo, ou da sua historicidade, características que lhe proporcionam uma significativa e temerosa funcionalidade.

Nesse contexto, Warat (1994, p. 104) afirma que o processo mitológico exprime a sua funcionalidade ao se colocar a serviço de uma ideologia política, como vem ocorrendo contemporaneamente, conforme será explicitado em seguida no contexto das reformas processuais do Judiciário. Dessa forma, recorrendo aos ensinamentos de Barthes, explicita que o mito é capaz de transformar a História em ideologia, de modo que "a significação mítica seria vista como reiterada afirmação periférica de um modelo axiológico geral".

Com tais características, o mito, ao congelar valores, exerce uma função socializadora, pois esvazia o real e tranquiliza (ou pacifica) as mentes, de modo que os homens aceitam a sua condição na sociedade. Inclusive, reconhecem tal condição como a única adequada, e, até mesmo, chegam a realmente desejá-la, o que culmina com o fato de que tais homens somente cultuem formas de poder que reproduzam ou que perpetuem aquela condição, ou aquele modelo (WARAT, 1994, p. 104-105). Mediante uma sociedade neutra e despolarizada, oportuniza-se a existência de uma "força social em termos de racionalidade supraracional e apriorística".

Nesse norte, o processo mítico propicia a simbolização de um conjunto de apreciações valorativas e de finalidades que muitas vezes são incompatíveis com uma dimensão coerente de tendências e conflitos não solucionados. Warat reconhece este processo mítico na racionalidade moderna, que também se faz presente no Processo Civil brasileiro. Dessa forma, atribui-se à racionalidade moderna as seguintes propriedades: impessoalidade, universalidade e anonimato. Nesse contexto, desconhece-se os seus emissores, uma vez que se abstrai ou se nega a existência dos mesmos, como se eles não estivessem obrigatoriamente inseridos em grupos sociais, comunidades raciais etc. (WARAT, 1994, p. 105).

Assim,

por traz da miragem de um emissor universal, levanta-se disfarçadamente a significação contextual inerente a todo processo de constituição de significados, já que conforme nos ensina a linguística, não há significados plenos e isentos de uma influência dos processos reais de comunicação (WARAT, 1994, p. 105).

Mediante os mitos, consegue-se a reconciliação das contradições sociais, como lucidamente explicita Warat, pois se projeta harmoniosamente a sociedade, com base em essências puras, e aparentemente intocadas: ilustra-se bem esta ideia quando se afirma que a função do intérprete consiste em "encontrar" o espírito do legislador na lei. Ovídio Baptista (2009b, p. 07) bem atesta a impossibilidade de tal tarefa no artigo Verdade e Significado, uma vez que, de acordo com os seus ensinamentos, a lei não contém apenas uma vontade, mas sim inúmeras vontades, ou inúmeros sentidos. Desse 
modo, os sentidos serão desvelados pelo intérprete de forma consoante com o seu contexto histórico e com as exigências políticas e sociais do seu tempo: harmonizando-se a letra da lei com as expectativas humanas que lhes são contemporâneas.

No entanto, evidencia-se que o processo argumentativo demonstrado por Warat se ampara no discurso mítico cumprindo duas funções: aludir e iludir. As complexidades são simplificadas e as contingências são universalizadas. Sob uma perspectiva abrangente, o processo mitológico complica a razão para simplificar o real, o que resulta por ocultá-lo (o real).

Defendendo uma necessária compreensão hermenêutica do Direito, Gadamer argumenta que os problemas hermenêuticos parecem especialmente difíceis de serem assimilados por um pensamento cientificista, porque lida com questões imprecisas para as ciências, enquanto questões de crítica, reflexão e discussão. Ao observar a hegemonia do conhecimento científico matematizado, que corrige "incansavelmente as faltas de êxito e produz constantemente novas tarefas de investigação científica" sempre em busca do progresso, Gadamer (2002, p. 292) denuncia estarmos caminhando em direção à cegueira, pois

no enrijecimento desse caminho rumo a uma configuração progressiva do mundo pela ciência perpetua-se um sistema no qual a consciência prática do indivíduo se submete resignada e cegamente ou então se rebela revoltosa, e isso significa, não menos cega.

O esquecimento do ser, a tensão entre verdade e método, e uma problematização exacerbadamente científica se esquecem de abordar os verdadeiros fins da sociedade e os problemas sociais vistos em sua substância. A preocupação com "o que fazer" e não com "o como fazer", a consciência da origem histórica e do futuro (do mundo vivido), não podem ser alcançados por um saber que somente se traduz em ciência. Sob a égide do paradigma Racionalista, mesmo quando, diante de um problema, a práxis da vida fala mais alto, silencia-se esta voz para se escutar a da ciência, pois somente ela confere legitimidade a uma decisão (GADAMER, 2002, p. 293).

Segundo Gadamer (2002, p. 293), a ciência moderna, surgida desde o século XVII, despreza o conhecimento da substância e subsume a realidade a um projeto matemático da natureza, analisando-a mediante critérios metodológicos e de experimentação. Através disso, busca-se o domínio da natureza pela ciência, mas, por outro lado, percebe-se o crescente acirramento do conflito entre consciência do progresso e consciência sociopolítica.

A preocupação com este conflito também é hoje essencial para o Direito: diagnosticada a crise do Poder Judiciário, e, mais precisamente, a crise do Direito Processual Civil, Ovídio Baptista questiona se tal crise é originária de um inadequado ou insuficiente desempenho funcional da jurisdição ou decorre de uma crise que "é reflexo de uma mais ampla e profunda crise institucional, que envolve a modernidade 
e seus paradigmas", crise na qual, o Direito, mergulhado na lógica da razão moderna, não é capaz de enxergar (BAPTISTA DA SILVA, 2009a, p. 89) ${ }^{4}$.

Para Ovídio Baptista, a crise não ocorre devido a um mau funcionamento da jurisdição. Contrariamente a maioria, o autor acredita que o Judiciário funciona bem - considerando-se os pressupostos à luz dos quais ele foi criado. Nesse sentido, ao observar as críticas realizadas pelos juristas a respeito da desfuncionalidade do atual modelo processual, essencialmente no que concerne à morosidade da prestação jurisdicional, Ovídio (2009a, p. 90-91) afirma que o modelo processual ora vigente não foi concebido com o intuito de atender à exigência de celeridade, valor fortemente presente na civilização pós-moderna.

Destarte, argumenta que o modelo de Processo Civil herdado, construído ainda no século XVII, visou atender aos ideais liberais iluministas de segurança e certeza, valores compatíveis com a ascensão da ideia de Direito visto como ciência. Assim, priorizou-se a segurança e a certeza em detrimento da efetividade da prestação jurisdicional, expressão esta que a sociedade pós-moderna também identifica como celeridade (BAPTISTA DA SILVA, 2009a, p. 91).

Reportando-se ao crescente papel que a sociedade atribui à celeridade no Direito Processual, Ovídio Baptista adverte que a separação entre Direito e Justiça, cuja origem vem do Direito Romano tardio, segue se aproximando cada vez mais do Poder. Tal situação recomenda precaução, pois a relação entre Direito e Poder "torna-se visível e mais nos desafia e inquieta quando suas consequências se tornam agressivas" (BAPTISTA DA SILVA, 2009a, p. 89).

Nessa esteira, afirma-se que "o Direito tornou-se uma função de outros interesses” (BAPTISTA DA SILVA, 2009a, p. 89), constatação que se coaduna com o pensamento de Jânia Maria Lopes Saldanha. Inspirada no conto literário de Ítalo Calvino, $\mathrm{O}$ visconde partido ao meio (CALVINO, 2008), que faz "uma inteligente metáfora sobre a ambivalência humana", a autora estabelece uma relação dialética entre Literatura e Direito com o intuito de retratar a atual conjuntura do Judiciário, cujo cenário vem se modificando e sendo moldado sob a influência de "outros interesses", podendo-se destacar, entre eles, o econômico (2010a, p. 79).

Nesse sentido, Jânia Saldanha afirma que o Judiciário brasileiro vivencia um cenário de forte pressão política e econômica, cuja principal consequência tem sido

4 Segundo Adalberto Hommerding (2007, p. 91-91), o "Processo Civil desenvolvido no quotidiano dos foros do país deita raízes no Direito romano, notadamente no que diz respeito ao procedimento ordinário, herança da cognitio extraordinarem. É possível afirmar, no entanto, que, historicamente, seus fundamentos podem ser encontrados na ideologia liberal, na filosofia da consciência (razão moderna), na busca da 'verdade' e da 'segurança jurídica' pelo método, e no respeito a institutos jurídicos protetores da individualidade e da autonomia da vontade, tais como o ato jurídico perfeito, o direito adquirido e a coisa julgada, elementos típicos do modelo de direito praticado no Estado Liberal". 
implantar reformas que buscam aperfeiçoar o sistema apenas em termos de fluxo e de produtividade (2010a, p. 76). Dessa forma, assim como o carpinteiro mestre Pedroprego do conto de Calvino - que, a mando de Visconde de Terralba, desenvolvia instrumentos de tortura e execução cada vez mais sofisticados, sem questionar as consequências da utilização dos mesmos - a autora indaga se a Jurisdição tem medido as consequências sociais de suas reformas para atender a uma sociedade premida pela pressa.

Além disso, elucida que o Judiciário está partido ao meio, tal e qual Visconde de Terralba - ora bom, ora mal - pois, orientada por critérios de quantificação - a Jurisdição se olvida de se guiar pelos preceitos constitucionais contidos na Carta de 1988.

Com base nisso, Jânia Saldanha denuncia a atividade paranormativa das agências transnacionais de fomento nos países periféricos, como o papel exercido pelo Banco Mundial no contexto das reformas processuais brasileiras. Mediante Documentos técnicos e Relatórios sobre o Judiciário, o Banco Mundial expõe as dificuldades e limitações dos sistemas de justiça brasileiros, vistas à luz dos seus critérios (econômicos). Como resultado dessa análise, o Banco apresenta diretrizes que visam orientar o Estado em dois aspectos: "institucional - o Poder Judiciário deve ser enquadrado num processo de modernização e; b) individual - os juizes são construtores de consenso" (SALDANHA, 2010a, p. 84).

Embora este órgão de fomento não atue no Judiciário instituindo normas, clara é sua influência, pois o Estado adere às suas ideias, que se apresentam amorfamente por meio da bandeira de "aprimoramento" da prestação jurisdicional. Retoricamente, apresenta-se comprometido com uma maior qualidade da prestação jurisdicional, "fantasiando", o seu verdadeiro e obscuro intuito: condicionar o Judiciário aos interesses econômicos (SALDANHA, 2010a, p. 84).

Sem o objetivo de esgotar e análise crítica a respeito da influência deste órgão nas reformas processuais brasileiras, em apertada síntese, narrar-se-á os valores para o aprimoramento da prestação jurisdicional contidos no Documento Técnico 319S O setor Judiciário na América Latina e no Caribe - do ano de 1996:

a)previsibilidade nas decisões; b) independência; c) eficiência; d) transparência; e) credibilidade; f) combate à corrupção; g) proteção à propriedade privada; h) acessibilidade; i) respeito aos contratos e j) mudança no ensino jurídico (SALDANHA, 2010a, p. 84).

À luz dos ensinamentos de Antoine Garapon (2008, p. 03), pode-se enumerar a primeira característica neoliberal presente nos valores acima transcritos: o império da padronização. Nesse sentido, objetiva-se padronizar a atividade jurisdicional, ou as decisões, mais precisamente, para que seja possível a adoção de comportamentos estratégicos, diante da previsibilidade das decisões judiciais.

Influenciados pela exigência de padronização (ou previsibilidade), ensejou-se, no contexto brasileiro, a criação da súmula vinculante e da súmula de repercussão geral dos recursos extraordinários e especiais pela Emenda Constitucional 45 de 2004. De 
acordo com Jânia Saldanha, tais medidas, ao estandartizarem as decisões, fragilizam o ato decisório, pois impedem a compreensão hermenêutica do processo: momento em que, à luz do caso concreto e dos preceitos constitucionais, encontra-se o sentido do texto, ou a norma do caso, construindo-se, assim, uma resposta constitucionalmente adequada a ele (caso), como tem incansavelmente defendido Lenio Luiz Streck ${ }^{5}$.

No entanto, prioriza-se um modelo de justiça estandardizado, em que se privilegia o pré-dado. Para tanto, a função do juiz restringe-se a encontrar os elementos presentes na súmula e prontamente aplicá-la, sob pena de eventuais sanções disciplinares.

Reportando-se ao valor eficiência, também presente no relatório, evidencia-se, mais uma vez, o incontestável matiz neoliberal do documento. Ocorrida a explosão da demanda da justiça em 1980, ocasionando, de acordo com Garapon, a massificação dos litígios por um lado, e a lentidão para a solução dos conflitos de outro, "a justiça precisa se repensar em termos de fluxo" (GARAPON, 2008, p. 03). Submetida à lógica neoliberal, o Judiciário é visto como um serviço dentre outros da imensa empresa de serviços que presta o Estado, por isso, deve ser muito eficiente, de modo que a questão não é mais tanto "saber se a justiça tem bem julgado, mas se ela eficientemente vem evacuando o fluxo de litígios que a ela estão sendo submetidos" (GARAPON, 2008, p. 04).

Em oposição a uma justiça morosa, própria do século XVIII, que não considerava o impacto social negativo gerado pela sua extrema demora, o neoliberalismo almeja respostas em "tempo real". Com isso, a lógica neoliberal desconsidera a importância de certo distanciamento temporal em relação aos fatos - o que permite cautela e prudência para se balizar a intervenção judicial - e prioriza um judiciário que estabeleça "um canal de compreensão' que demonstre a sua utilidade para os olhos do público" (GARAPON, 2008, p. 07). Assim, o público deve receber respostas imediatas do Judiciário, para que seja, então, considerado eficiente. Daí também se evidenciam valores como transparência e credibilidade.

Jânia Saldanha bem retrata a influência deste valor na Emenda Constitucional número 45 de 2004, pois ela provocou expressivas mudanças funcionais. Nesse sentido, os magistrados passaram a ser promovidos de acordo com critérios essencialmente vinculados à produtividade, e não à qualidade da sua atuação: avalia-se se produziram decisões em tempo razoável e se decidiram de acordo com as súmulas dos tribunais superiores, sem minimamente considerar a qualidade das decisões.

5 De acordo com Lenio Luiz Streck (2009, p. 27), “há algo em que é 'dado à nossa mente', como se pode perceber nas súmulas (e também na construção de conceitos prêt-à-pôrtes que recheiam os manuais jurídicos). As súmulas 'carregariam', assim, a substância de determinados casos. Tranportada (ess)a essência (substância) para a mente, forma-se o conceito, que é representado pelo enunciado sumular, que passa a ser 'o dado'. Consequentemente, o intérprete fica assujeitado a esse dado, isto é, a esse conceito de caráter universal (pensemos nisso também na aplicação da repercussão geral pelo STF e da nova Lei dos Recursos - 11.672, pelo STJ). 
De acordo com Garapon, criam-se "códigos de conduta", que visam definir stardands de comportamento para restringir as atividades dos destinatários de tais regras a um determinado padrão. Assim, se tais regras não são obrigatórias, são, ao menos, fortemente recomendáveis, de modo que a adequação a tais comportamentos contribui significativamente para eventuais promoções, além de também protegerem os funcionários quando submetidos a processos disciplinares (GARAPON, 2008, p. 04).

Diante de tais mudanças, importante é a passagem de Garapon em que ele adverte acerca dos riscos de uma justiça pautada somente pelo que é mensurável pelo tempo e pelo dinheiro, em detrimento daquilo que não se pode medir, pois “aquilo que não é mensurável é imediatamente relegado ao âmbito do 'não apurável', e, por conseguinte, tornam-se dados secundários".

Ainda, importante é a crítica de Garapon (2008, p. 07) quando afirma que o modelo neoliberal

aborda o Direito não mais de seu interior, como um conjunto de regras que exprimem a vontade geral da sociedade, mas de seu exterior, adotando o ponto de vista dos consumidores do direito, para os quais o direito é apenas uma informação que eles devem considerar nas suas decisões.

Evidencia-se a presença desta mudança de ponto de vista à luz do exemplo ora discutido, concernente ao papel exercido pelo Banco Mundial diante das reformas processuais, bem como diante das outras reformas mencionadas que transcendem o âmbito do Processo Civil. Assim, Garapon afirma que, no cenário da mundialização, os diferentes sistemas de justiça se encontram em concorrência, permitindo que os consumidores exerçam o forum shopping, atividade que permite que os consumidores decidam qual jurisdição irão se submeter de acordo com a jurisprudência e procedimentos que lhes são mais favoráveis. Assim, as diferenças entre as jurisdições se tornam vantagens e desvantagens comparativas para os consumidores.

Percebe-se em tais diretrizes traços de um forte comprometimento com a lógica neoliberal, ainda que assim não se apresentem. Conforme Michel Foulcault (2008, p. 164) "a relação entre economia de concorrência e um Estado não pode mais ser de delimitação recíproca de áreas diferentes". Precisamente, "não haverá o jogo do mercado, que se deve deixar livre, e, depois, a área em que o Estado começará a intervir". A concorrência - essência do mercado - só tem sua existência viabilizada quando se tem uma governamentalidade ativa por detrás. Assim, Foucault (2008, p. 165) denuncia que há uma "justaposição total” dos mecanismos do mercado atrelados à concorrência e da política governamental.

Ao contrário do que superficialmente possa parecer, a economia de mercado muito antes de subtrair o governo - ela orienta, indica (Banco Mundial), "constitui o indexador geral sob o qual se deve colocar a regra que vai definir todas as ações 
governamentais". Nessa perspectiva, governa-se para o mercado, no lugar de se governar por causa do mercado. Muito antes de se enquadrar no signo do laissez-faire, o neoliberalismo atuará positivamente, "sob o signo da vigilância, de uma atividade, de uma intervenção permanente".

Com base nisso, Warat merece ser lembrado quando Garapon afirma que a sociedade atual está sendo despolitizada, pois o neoliberalismo vem desenhando na atividade jurisdicional um modelo de indivíduo dissociado do homem ${ }^{6}$. Alcança-se a despolitização da sociedade a partir do momento em que o sistema se constrói priorizando, essencialmente, valores como a liberdade individual - indispensável para que o indivíduo racional assuma comportamentos estratégicos - em detrimento de outras formas de liberdade. Assim constrói-se uma política “comprometida em poder se libertar de todas as deliberações, sob um direito que não se perturba com a ordem estabelecida, sob um tempo em que não se faz mais história" e sob um modelo de indivíduo, e não de homem, que não pensa em nada além de si mesmo (GARAPON, 2008, p. 27).

Assim, nas palavras de Garapon (2008, p. 24):

aliando-se a tanta radicalização, o mundo da justiça neoliberal tem por escopo colocar um fim prematuro à tensão inelutável entre os pontos de vista opostos: acalma-se a inquietude concernente às instituições de justiça, inquietude que caracteriza, ao mesmo tempo, uma sociedade democrática. Evidencia-se a eficiência, a universidade de interesses, a precisão dos dados mensuráveis, fornecidos às instituições, e à opinião, um anti-ansiolítico, que inibe a função deliberativa da democracia.

Nesse sentido, percebe-se que a sociedade neoliberal constrói mitos, bem ao modo discutido anteriormente, à luz dos ensinamentos de Warat. Assim, congelam-se valores - como liberdade individual, eficiência, presteza, previsibilidade - e se esvazia o real (para que se pacifiquem as mentes), eliminando-se o espaço para que escolas de pensamento vinculadas a uma ou outra ideologia manifestem opiniões muitas vezes contrárias ao paradigma dominante (como se este não sofresse a influência de nenhuma ideologia). Nesse contexto, Garapon afirma que, em lugar de se incriminar escolas de pensamento que defendem opiniões divergentes, dever-se-ia, pelo contrário, ouvi-las e respondê-las, pondo em evidência os seus verdadeiros propósitos, que não raro também

6 Importante é a passagem em que Adalberto Hommerding (2007, p. 92) versa que "o processo, que é o método para exercício da jurisdição não tem sido democrático. Ainda não se constitui em um instrumento de liberdade e democracia. Não permite 'escolhas' e 'não permite o encontro do homem com a vida (WARAT). É, sim, uma estrutura de poder, uma organização de poder formalmente considerada, tendo por fim a atuação da ordem como bem objetivamente considerado. Essa estrutura de poder, que tem por finalidade a atuação da ordem, nada mais é do que uma forma para a conservação do poder, o que significa a manutenção dos privilégios que, em favor dos grupos dominantes, o ordenamento jurídico consagrou. Fruto de uma sociedade capitalista, para quem o lucro, a liberdade para contratar e a segurança jurídica são alguns dos valores mais caros, o processo, 'método' de realização do direito, não permite opções ao cidadão: ou a ele se submete ou não tem escolha para buscar a realização do seu direito". 
estão encobertos: assim se estabelece um espaço para o diálogo democrático. Invocando Lefort, Garapon ressalta que é inerente à democracia uma inquietude permanente ${ }^{7}$.

Contra uma sociedade neutra e despolarizada, deve-se questionar falsas evidências presentes no discurso neoliberal, além de se revelar quem são os emissores deste discurso (como, por exemplo, as reformas processuais contidas na emenda 45 de 2004 que fortemente aderem às ideias presentes no relatório de autoria do Banco Mundial). Deve-se questionar, igualmente, se as apreciações valorativas e finalidades próprias ao modelo neoliberal de Estado solucionarão de modo efetivo os problemas sociais, como a ausência de políticas públicas, a excessiva concentração de renda e a não concretização dos direitos sociais - ideais presentes na Constituição de 1988, comprometida com a transformação da realidade social ${ }^{8}$.

Ao que parece, as reformas processuais que buscaram eficiência na prestação jurisdicional, fortemente estimuladas pelo Banco Mundial, não foram capazes de

7 Acerca de um cenário democrático constitucionalmente garantido, Canotilho (2001, p. 141-142) versa que "excluindo os casos em que o poder de facto impõe um texto constitucional (intervenção, ocupação, putsch) - nos quais a ideia de compromisso se esbate ou anula - as constituições democráticas, elaboradas 'democraticamente', pressupõem uma realidade social, plural, antagónica e em tensão, daí resultando que muitas das suas normas (abstraindo de algumas partes fundamentais) são um verdadeiro compromisso entre ideias, projectos, programas e interesses dos 'grupos constitucionais'. Esta consideração aponta para a necessidade de, numa teoria da constituição, se ter em conta não apenas a tarefa ou função de 'unidade' da constituição, mas também de 'oposição', o ‘antagonismo' e a ‘tensão', conscientemente aceites na estrutura normativo-constitucional. A constituição, ao aspirar transformar-se em projeto global normativo (do Estado e da sociedade) aceita, sem harmonismos ou universalismos redutores, as contradições existentes na realidade".

8 Nesse contexto, relevante é a problemática envolvendo o papel da Constituição tão bem retratado por Canotilho (2001, p. 139-140): “(...) o ‘consenso'a obter numa constituição é um 'consenso negativo' - aquilo que não se deseja ao esboçar-se a institucionalização normativo-constitucional - ou será também um 'consenso positivo’ sobre conformação concreta da realidade - aquilo que se quer como conteúdo concreto da solução constitucional? Por outras palavras: consenso é um 'consenso-quadro' ou é um 'consenso de fundamento material'? O consenso constitucional deve ser um 'consenso abstracto' e 'mínimo' ou deve ser um 'consenso concreto’? Em termos práticos: o consenso fundamental e abstracto sobre a 'dignidade da pessoa humana' deve limitar-se a um consenso expresso no simples postulado de que a 'pessoa' não deve ser convertida em objeto de domínio, ou deve ter refracção concreta noutros domínios, como, por exemplo, consagração de direitos econômicos, sociais e culturais? As considerações anteriores subentendem já a problemática fundamental do consenso na constituição: partindo-se do facto de que uma constituição hoje não se reduz a uma 'norma' limitadora do poder nem a um 'momento de decisão', antes se caracteriza como projeto de ordenação do processo político e de conformação social, o problema central reside na fixação dos Tatbestände de uma vida coletiva, sobretudo nos aspectos dirigidos ao 'futuro'. Precisamente por isso, quando se discute a necessidade de um 'consenso constitucional' e se defende o regresso a um tipo liberal de constituição no sentido de exclusivo instrument of government escamoteia-se, de forma deliberada, o próprio problema do consenso: os fundamentos materiais do Estado, os princípios segundo os quais se devem reger os actos dos poderes políticos e os fins a prosseguir colectivamente". Ainda, segue Canotilho (p. 140-141): "O 'consenso constitucional' é um resultado e não um dado preexistente com substancialidade autónoma ou derivado de 'unidades' como 'estado', 'consenso social', 'unanimidade ideológica'. A constituição como 'sistema parcial' da sociedade não fica isenta das constradições, antagonismos, divergências e conflitos reinantes no contexto global, social, político e económico. Daí que o 'clausulado constitucional' se apresenta, muitas vezes, formalmente, como produto de um 'consenso' (ou contrato) entre os constituent groups, sob o ponto de vista intrínseco é um verdadeiro "compromisso"”. 
solucionar os problemas do Poder Judiciário. Jânia Maria Lopes Saldanha bem demonstra que, após oito anos do Documento Técnico n. ${ }^{\circ} 319 \mathrm{~S}$, o Banco Mundial “quase concomitantemente à entrada em vigor da Emenda Constitucional n. ${ }^{0} 45$ de 2004, apresenta o Relatório 32789-BR, intitulado 'Fazendo com que a Justiça conte', de 30 de dezembro de 2004" (SALDANHA, 2010a, p. 87). Nele, o Banco afirma que o aumento nos valores orçamentários não será suficiente para solucionar os problemas do judiciário. Desse modo, estabelece novas medidas: aumentar a eficiência do judiciário, reduzir a ineficiência de certos órgãos extrajudiciários que condicionam as respostas dos juízes e empreender esforços para que se reduza a própria demanda.

Mais uma vez, mostra-se que o problema é estrutural: tanto o é que de reformas pontuais no Código de Processo Civil, passou-se à discussão de um novo Código de Processo Civil (NUNES; BARROS, 2010, p. 15-16). Tal situação denota a necessidade de que a ciência processual viva uma transformação na sua estrutura, ou que seja "refundada", para usar a expressão cunhada por Angela Espindola (2008, p. 30). Nesse sentido, necessário é saber "os limites da desconstrução que permanece prisioneira do sistema que a desconstrói", bem como reconhecer que para um problema humano, necessária é uma resposta culturalmente humana (SALDANHA, ESPINDOLA, ISAIA, 2010b, p 167). É, em razão disso, que a hermenêutica filosófica cumpre um papel central, pois possibilita uma reconciliação entre razão prática e razão teórica, de modo que não mais se faça um estudo do Direito "filtrado" do mundo vivido, ou seja, dissociado dos atuais problemas da (pós) modernidade, entre os quais alguns já foram mencionados (ausência de políticas públicas, concretização dos direitos sociais, diminuição da desigualdade existente entre ricos e pobres).

Nesse norte, Gadamer (2003, p. 25) afirma que "as ciências da natureza constituem um modelo para as 'ciências humanas' na medida em que as últimas se submetam ao ideal de um valor científico autônomo e fundado". O que se quer, portanto, é que as ciências humanas não se submetam à metodologia das ciências naturais, mas sim que se espelhem nela como modelo de ciência auto-fundada. Desse modo, Gadamer bem revela que as ciências humanas, ainda que busquem apoio na filosofia contemporânea, ainda assim - para se garantirem de um bom conhecimento científico - retornam ao modelo das ciências da natureza para construírem os seus métodos histórico-críticos (GADAMER, 2003, p. 21).

Considerando isso, o autor alemão debate-se em torno da questão das ciências humanas buscarem, analogamente às ciências naturais, um método que - embora lhe seja próprio - tenha as características de ser prévio e único para todos os domínios de sua aplicação. Em seguida, questiona se não seria inadequada a ideia cartesiana de método para as ciências sociais. Bem como, porque não se adotar o conceito grego antigo de método. 
Nessa esteira, Gadamer explica que a ideia de Aristóteles de um método único, determinado antes mesmo de se conhecer a coisa a ser investigada, constitui perigosa abstração. Assim, questiona se um método que se permita afastar-se do objeto de estudo, ou do campo investigado, tão característico nos métodos próprios das ciências naturais, "não leva, nas ciências humanas, a uma compreensão equivocada do modo de ser específico do seu próprio campo". Desse modo, Gadamer acerca-se ao pensamento hegeliano, defendendo que "todo método é um método ligado ao próprio objeto", isto é, é o objeto que condiciona o método, ele é quem determina o método adequado para investigá-lo (GADAMER, 2003, p. 22).

Esta conclusão hegeliana, compreendida durante o século XIX, parecia absurda à época, pois era evidente que as ciências da natureza propiciavam um competente modelo para que se chegasse a conclusões. Nesse contexto, longe de se querer construir um modelo de saber auto-fundado para as ciências humanas, J. S. Mill buscou demonstrar que o método indutivo, próprio das ciências empíricas, também era apto às ciências morais. Gadamer afirma que tal entendimento não foi nada mais que a confirmação da tradição inglesa secular que já na introdução do Tratado da natureza humana de Hume afirmava que a procura de uniformidades, regularidades e leis com previsão de fatos e ocorrências particulares não constituíam apenas um modelo de conhecimento restrito às ciências empíricas, englobando também as ciências morais (GADAMER, 2003, p. 22).

Nesse sentido, Gadamer versa que o método indutivo, sem dúvida, contribuiu substancialmente para a descoberta de regularidades na psicologia de massas, por exemplo, merecendo, portanto, o reconhecimento de um sucesso incontestável. No entanto, ele afirma que "a simples constatação de que a descoberta de regularidades realiza um progresso efetivo nas ciências humanas, não faz mais, em última instância, do que encobrir o verdadeiro problema posto para essas ciências" (GADAMER, 2003, p. 23).

Com base na citação acima transcrita, Gadamer (2003, p. 23) afirma que o modelo indutivo humiano não permite incluir a essência da experiência ao estudo, e assim argumenta que não será encontrando regularidades e nem aplicando dados históricos que o conhecimento histórico será apreendido, pois o conhecimento histórico transcende a possibilidade de englobar um caso particular a uma regra geral. $\mathrm{O}$ que verdadeiramente ele visa é "antes compreender um fenômeno histórico em sua singularidade e em sua unicidade".

Tais discussões servem para que se perceba a importância do círculo hermenêutico para uma correta interpretação do Direito, bem como para uma correta avaliação dos limites das reformas que vem ocorrendo no Direito Processual Civil. Munido dos ensinamentos de Heidegger, Gadamer (2003, p. 60) traz a lume a questão de que o círculo hermenêutico não pode ser depreciado e qualificado como vicioso, pois ele encerra em si uma autêntica possibilidade do saber mais original, que só pode ser 
corretamente apreendido quando se reconhece que toda explicitação, ou toda interpretação, tem como intuito - primeiro, permanente e último - não permitir que conhecimentos e concepções prévias se imponham pelo que se antecipa nas noções e intuições populares. Pelo contrário: deve-se se assegurar o tema científico e buscar o desdobramento de tais antecipações de acordo com a "coisa mesma".

Assim se delineia as exigências que se impõem à prática da compreensão: "elas descrevem a maneira pela qual a interpretação sempre procede quando visa a uma compreensão cuja medida é a "coisa mesma" (GADAMER, 2003, p. 60). Nesse norte, ao autor alemão afirma que:

toda interpretação autêntica deve se precaver contra a arbitrariedade de ideias barrocas que afloram ao espírito, bem como contra as limitações provenientes de hábitos inconscientes de pensamento. É evidente que, para ser autêntico, o olhar da investigação deve dirigir-se à "coisa mesma", de tal modo que ela seja apreendida, por assim dizer "em pessoa" (GADAMER, 2003, p. 60).

Ainda com Gadamer, importante é a passagem em que ele versa que tão logo a “coisa mesma" desperte os primeiros elementos compreensíveis, o intérprete já faz o primeiro esboço do projeto, conferindo uma significação a todo texto. No entanto, os primeiros elementos significativos somente vêm a lume se o intérprete se entregar a leitura do "texto" ou da "coisa mesma" de modo minimamente interessado. Nesse sentido, na medida em que o intérprete faz progressos na decifração do objeto ou na leitura do texto, o seu primeiro projeto começa a sofrer gradualmente modificações, de forma que o projeto será constantemente revisado.

Nesse sentido, o autor afirma que sem uma revisão do primeiro projeto, não há elementos para que se possa constituir uma nova base de significado. Destarte, projetos discordantes permanecem ambicionando construir uma unidade de significação até que ocorra essa "primeira" interpretação, que propicia uma renovação do projeto em bases mais adequadas à “coisa mesma". Quem se deixa levar apenas pelas suas concepções preliminares corre o risco de que suas antecipações não correspondam ao que a "coisa mesma" realmente é (GADAMER, 2003, p. 61).

Por isso, é preciso analisar com parcimônia as reformas processuais implantadas em um passado recente, assim como as que estão por vir, pois um olhar cuidadoso exige estar atento à influência neoliberal no contexto das reformas processuais brasileiras. De acordo com Garapon, “o modelo neoliberal se substitui traiçoeiramente aos princípios da justiça clássica, por outros critérios como a eficiência, as vantagens comparativas ou a segurança", de modo que tais princípios imperam perante os outros, pois são metamorais: apresentando-se como os únicos possíveis, os únicos evidentes.

Em função de serem transcendentes e suficientes por si, não necessitam se unir aos valores tradicionais da justiça clássica, o que propicia, inevitavelmente, a laicização das instituições (GARAPON, 2008, p. 26). Estas passam então a serem revaloradas de 
acordo com critérios como concorrência e empreendimento. Assim, acaba-se por afastar o Direito daquilo que lhe é mais caro: a Justiça. E o confunde, cada vez mais, com a ideia de Poder. Desse modo, recomendável seria apontar as escolhas implícitas do ideal democrático neoliberal, que recorrentemente apresentam-se como evidências.

\section{CONSIDERAÇÕES FINAIS}

$\mathrm{Na}$ primeira parte do artigo, buscou-se revelar a origem histórica do modelo processual que permeia no cenário processual brasileiro, de cunho racionalista e individualista - significativamente condicionado pelos movimentos culturais renascentistas, bem como pela Contra Reforma. O nominalismo ockhamiano constrói as vigas que sustentam o modelo positivista, momento em que o Direito se dissocia da Justiça e ganha o sentido de Poder.

Como discutido no primeiro capítulo, o Direito (e, de modo mais abrangente, as ciências humanas) influenciado pelos ideais iluministas, apropriou-se dos métodos científicos próprios das ciências naturais-exatas-matemáticas, que tinham como expoentes Galileu, Descates, Newton, com o intuito de atender aos valores de segurança e certeza. No entanto, evidenciou-se o problema daí decorrente, pois, ao pautar-se o Direito pela lógica das ciências naturais, impede-se que o mesmo seja refletido para além de contextos factuais ideais, isto é: de acordo com uma realidade em conflito e plural, não submetida a reducionismos universalizantes como argumenta Canotilho, que nem mesmo configura o de Estado Democrático e Social de Direito desenhado pela Constituição de 1988.

Diante da impossibilidade de uma reflexão problemática acerca do Direito sob influência de um pensamento cientificista, demonstrou-se a necessidade de se construir um modelo de saber auto-fundado para as ciências humanas e, portanto, para o Direito: este é o caminho para que se alcancem respostas humanas para um problema culturalmente humano. Nesta jornada, a hermenêutica filosófica exerce um papel central, pois é ela quem oportuniza uma compreensão do Direito não deslocado do mundo vivido. Nesse contexto, as ciências naturais cumprem meramente o papel de servir como um modelo de saber que detém autonomia, não exercendo maior influência que esta, portanto.

Guiando-se por uma compreensão hermenêutica do Processo Civil brasileiro, impede-se que a aridez própria do Racionalismo propicie a inconsciente absorção de valores neoliberais, estimuladores das reformas processuais ora mencionadas, que contribuem para que o Judiciário se reduza a um mero prestador de serviços aos atores neoliberais: empresas transnacionais, consumidores etc.

Assim sendo, o presente artigo buscou retratar a presença ora imperante do valor eficiência nas reformas processuais, descomprometido com a efetividade do conteúdo que o processo carrega, isto é, os Direitos Fundamentais das partes. Com isso, buscou- 
se mostrar a necessidade de que ambos os valores - eficiência e efetividade - harmonizemse, conciliem-se, recuperando-se, desse modo, um modelo de Direito compromissado com a Justiça, e não apenas com o Poder.

\section{REFERÊNCIAS}

BAPTISTA DA SILVA, Ovídio A. Da função à estrutura. In: Lenio Luiz; BOLZAN DE MORAIS, José Luis (Org.). Constituição, Sistemas Sociais e Hermenêutica - Anuário do Programa de Pós-graduação em Direito da UNISINOS: Mestrado e Doutorado. São Leopoldo: UNISINOS, 2009a.

BAPTISTA DA SILVA, Ovídio A. Jurisdição e Execução na Tradição Romano-Canônica. 3. ed. Rio de Janeiro: Editora Forense, 2007.

BAPTISTA DA SILVA, Ovídio A. Processo e Ideologia - O Paradigma Racionalista. 2. ed. Rio de Janeiro: Editora Forense, 2006.

BAPTISTA DA SILVA, Ovídio A. Verdade e Significado. In: Centro Nacional de Cultura e Justiça - CENAJUS. 2009b. Disponível em: < http://www.cenajus.org/moodle/mod/forum/discuss. php?d=222> . Acessado em 10 de julho de 2011 .

BAUMER, Franklin L. O pensamento europeu moderno - Volume I, Séculos XVII e XVIII. Tradução: Maria Manuela Alberty. Lisboa: Edições 70.

CALVINO, Ítalo. O visconde partido ao meio. São Paulo: Companhia das Letras, 1996.

CANOTILHO, José Joaquim Gomes. Constituição Dirigente e Vinculação do Legislador - contributo para a compreensão das normas constitucionais programáticas. 2. ed. Coimbra: Coimbra Editora, 2001.

ESPINDOLA, Angela Araujo da Silveira. Superação do Racionalismo no processo civil enquanto condição de possibilidade para a construção das tutelas preventivas: um problema de estrutura ou função? - (ou: porque é preciso navegar em direção à ilha desconhecida e construir o direito processual civil do Estado Democrático de Direito?). Tese de Doutoramento - Universidade do Vale do Rio dos Sinos. Defendida em 08 de abril de 2008. Disponível em < http://www.unisinos.br/mestrado-edoutorado/direito/teses-e-dissertacoes >. Acessado em 10 de julho de 2011.

FOUCAULT, Michel. Nascimento da Biopolítica. Tradução: Eduardo Brandão. São Paulo: Martins Fontes, 2008.

GADAMER, Hans-Georg. O problema da consciência histórica. Tradução: Paulo César Duque Estrada. 2. ed. Rio de Janeiro: Fundação Getúlio Vargas, 2003.

GADAMER, Hans-Georg. Verdade e Método II. Tradução: Enio Paulo Giachini. 5. ed. Bragança: Editora Universitária São Francisco; Petrópolis: Vozes, 2002.

GARAPON, Antoine. Um novo modelo de justiça: eficiência, atores racionais, segurança. Tradução: Jânia Maria Lopes Saldanha. In: Revista Espirit, n. 349, novembro de 2008.

HOMMERDING, Adalberto Narciso. Fundamentos para uma compreensão Hermenêutica do Processo Civil. Porto Alegre: Livraria do Advogado, 2007.

NUNES, Dierle; BARROS, Flaviane Magalhães de. As Reformas Processuais Macroestruturais Brasileiras. In: BARROS, Flaviane Magalhães de; BOLZAN DE MORAIS, José Luis (Coord.). Reformas do Processo Civil: perspectivas constitucionais. Belo Horizonte: Fórum, 2010. ISBN: 978-85-7700-404-1. 
SALDANHA, Jânia Maria Lopes. A jurisdição partida ao meio. A (in)visível tensão entre eficiência e efetividade. In: STRECK, Lenio Luiz; BOLZAN DE MORAIS, José Luis (Org.). Constituição, Sistemas Sociais e Hermenêutica - Anuário do Programa de Pós-graduação em Direito da UNISINOS: Mestrado e Doutorado. São Leopoldo: UNISINOS, 2010a.

SALDANHA, Jânia Maria Lopes. A paradoxal face "hipermoderna" do processo constitcional: um olhar sobre o direito processual brasileiro. In: Estudios Constitucionales, v. 8, n. 2 de 2010. Diponível em: < http://redalyc.uaemex.mx/src/inicio/ArtPdfRed.jsp?iCve $=82015660020>$. Acessado em 10 de julho de 2011.

SALDANHA, Jânia Maria Lopes. Do funcionalismo processual da aurora das luzes às mudanças processuais estruturais metodológicas do crepúsculo das luzes: a revolução paradigmática do sistema processual e procedimental de controle concentrado da constitucionalidade no STF. In: STRECK, Lenio Luiz; BOLZAN DE MORAIS, José Luis (Org.). Constituição, Sistemas Sociais e Hermenêutica Anuário do Programa de Pós-graduação em Direito da UNISINOS: Mestrado e Doutorado. São Leopoldo: UNISINOS, 2009.

SALDANHA, Jânia Maria Lopes; ESPINDOLA, Angela Araujo da Silveira; ISAIA, Cristiano Becker. Interrogações sobre Princípios Processuais Previstos no Projeto de Novo Código de Processo Civil. In: BARROS, Flaviane Magalhães de; BOLZAN DE MORAIS, José Luis (Coord.). Reformas do Processo Civil: perspectivas constitucionais. Belo Horizonte: Fórum, 2010b.

ISBN: 978-85-7700-404-1.

STRECK, Lenio Luiz. Hermenêutica jurídica nos 20 anos de Constituição: condições e possibilidades para a obtenção de respostas corretas. In: STRECK, Lenio Luiz; BOLZAN DE MORAIS, José Luis (Org.). Constituição, Sistemas Sociais e Hermenêutica - Anuário do Programa de Pós-graduação em Direito da UNISINOS: Mestrado e Doutorado. São Leopoldo: UNISINOS, 2009.

VILLEY, Michel. A formação do pensamento jurídico moderno. Tradução: Claudia Berliner. São Paulo: Martins Fontes, 2005.

WARAT, Luis Alberto. Introdução Geral ao Direito I - Interpretação da lei. Temas para uma reformulação. Porto Alegre: Fabris, 1994. 